\title{
The relevance of empirical political science in Austria: Ask important questions, study them rigorously, and let people know
}

Laurenz Ennser-Jedenastik, Thomas M. Meyer, Markus Wagner

University of Vienna, Department of Government, Austria

laurenz.ennser@univie.ac.at, thomas.meyer@univie.ac.at, markus.wagner@univie.ac.at

\begin{abstract}
In recent years, political science in Austria has become more open, more internationally oriented, and more visible internationally. While all these developments must clearly be welcomed, they do not automatically translate into greater relevance of the discipline. In this contribution we outline four criteria that need to be fulfilled for empirical research in political science to become relevant: the importance of the problem under study, the generalizability of the findings, the appropriateness of the research design, and the extent to which it is communicated within the discipline and beyond. Based on these criteria we discuss steps that political scientists working not only in Austria but also on Austria can take to improve the relevance of their research.
\end{abstract}

\section{Keywords}

communication, relevance, research design, research questions

\section{Die Relevanz empirischer Politikwissenschaft in Österreich: Wichtige Fragen stellen, sie rigoros analysieren und die Welt davon wissen lassen}

\section{Zusammenfassung}

Die Politikwissenschaft in Österreich hat in den vergangenen Jahren eine zunehmende Öffnung, internationale Ausrichtung und internationale Sichtbarkeit erfahren. So sehr diese Entwicklungen zu begrüßen sind, gehen sie nicht automatisch mit größerer Relevanz der Disziplin einher. In diesem Beitrag stellen wir vier Kriterien vor, die erfüllt sein müssen, damit empirische Politikwissenschaft relevant wird: die Bedeutung des untersuchten Problems, die Verallgemeinerbarkeit der Erkenntnisse, die Angemessenheit des Forschungsdesigns sowie das Ausmaß der Kommunikation inner- und außerhalb des Fachs. Auf Basis dieser Kriterien diskutieren wir Maßnahmen, die die Relevanz von politikwissenschaftlicher Forschung in - aber auch über - Österreich verbessern können.

\section{Schlüsselwörter}

Kommunikation, Relevanz, Forschungsdesign, Forschungsfragen

The authors have declared that no competing interests exist. 


\section{Introduction}

In the past decade or so, political science in Austria has undergone significant change. While the political science community remains relatively small (in 2016, the Austrian Political Science Association had fewer than 200 paying members), there has been a notable trend towards internationalization. For one, political scientists in Austria now increasingly engage in international debates. This trend is clearly visible in publication activity in the field. Figure I shows that the number of publications in SSCI journals in the categories of political science and international relations including researchers with an Austrian affiliation is three- to four-times higher than 20years ago. At about 0.7 $\%$ of the worldwide output in 2016, Austria's contribution is larger than its share of the world's population (about 0.0I\%) and, more importantly, its share of global GDP (about 0.5\%). In addition, the political science community in Austria has become more open: there has been an increased influx into Austrian universities and research institutions of academics who have worked or were trained abroad.

So, political science in Austria is clearly more visible than in the past, at least in terms of internationally published research. Administrative officials with beancounting tendencies would stop here. Indeed, many research institutions and funding agencies, including those in Austria, use quantified measures of international visibility (e.g. the number of publications in SSCI-listed journals) as a core metric of research impact. Yet, it would be a mistake to interpret such measures of visibility as a sufficient indicator of "relevance" which - as Senn and Eder (2018) highlight in their contribution to this special issue - is a multi-faceted concept that may refer to the (political science) discipline, citizens, and policy-making.

First, international visibility (e.g. as measured in journal rankings and citation counts) is primarily an indicator of whether research engages with disciplinary debates and thus contributes to questions discussed within the political science community. To be sure, international visibility and academic relevance are likely to be correlated. It is easier to place one's research in highly-ranked international journals if it is seen as relevant by peers, but that does not mean that all (or even most) research published in such outlets is of high academic relevance. Hence, the first question is how Austrian political science can best contribute to producing significant theoretical and empirical advances in the field.

Second, publication activity may say little about the civic or political relevance (Senn/Eder, 2018) of the research conducted. While societal and disciplinary debates are not entirely divorced from one another, the gap between the two can be large at times. After all, scientists fall for (irrelevant) fads and fashions just as much as other people, and questions and conflicts that take on great importance in academic circles may often contribute little to larger questions. To be sure, we do not view academic relevance as a strictly necessary condition for societal relevance, yet in

Figure 1: Proportion of all SSCI publications in political science and international relations with Austrian institutional affiliation, 2000-2017

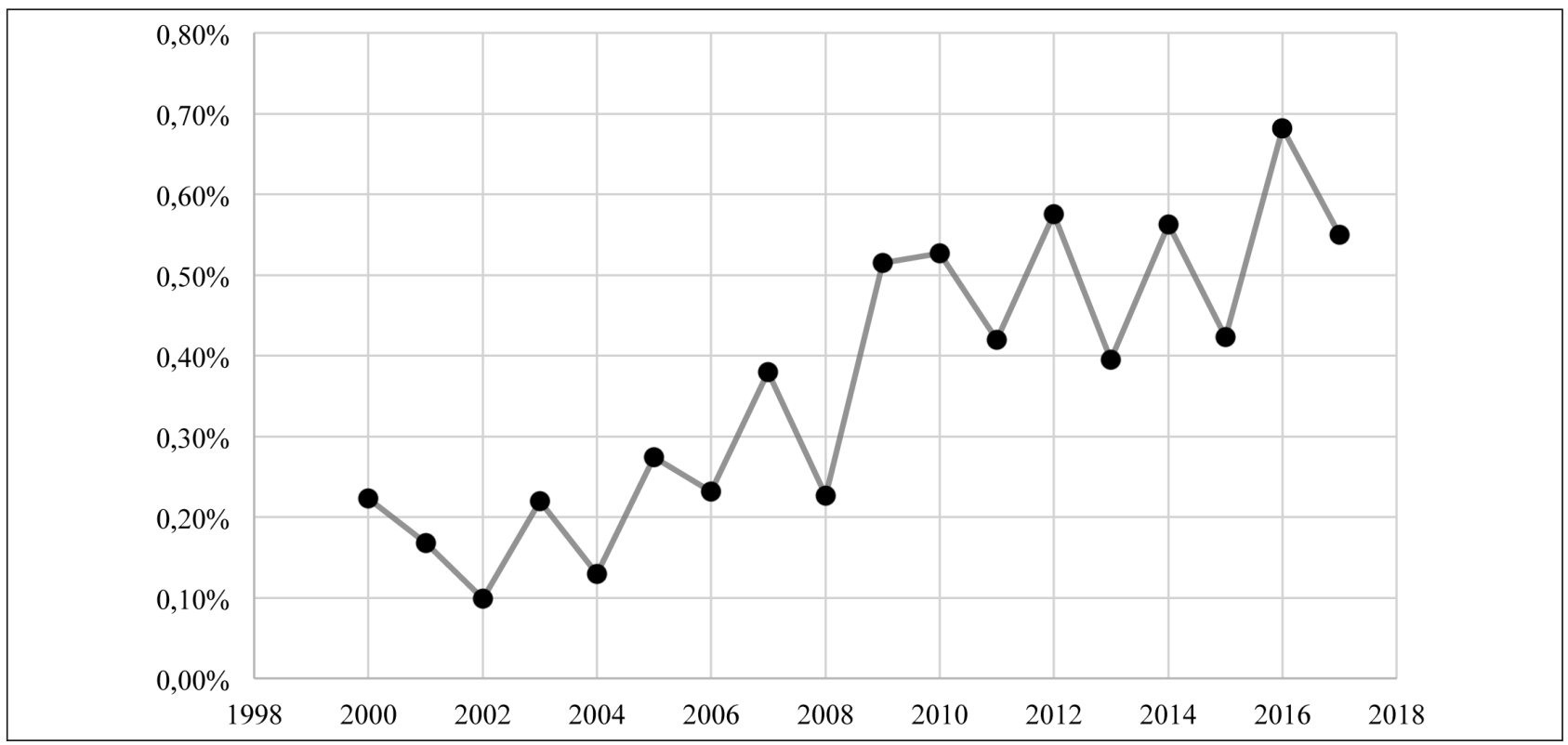

Note: The graph displays the proportion of publications in $\mathrm{SSCl}$ journals in the categories political science and international relations with an institutional affiliation to one of the main social science research universities in Austria (Vienna, Innsbruck, Salzburg, Graz, Linz, Klagenfurt, WU Vienna) or the Austrian Academy of Sciences (retrieved from www.webofknowledge.com on 13 September 2018). Numbers above the dots denote the respective absolute number of SSCI publications per year. The Institute of Advanced Studies (IHS) is not included in this count since it is not listed in the Web of Science index of organizations. 
practice, research of high academic relevance may be more impactful in the civic and political sphere. We need to ask how we can ensure that our research addresses and engages with questions that are relevant to citizens and policymakers. This is particularly important for young scholars who operate in an increasingly competitive research environment. They are increasingly facing a dual challenge to produce high-quality output for an academic audience (e.g. journal publications) and the society at large.

This second question has caused significant debate and reflection within other political science communities as well. In the United Kingdom, Flinders (2013) and Riddell (see John 20I2) attacked the increased professionalization of academics in the discipline, as evidenced by the focus on peer-reviewed journal publications and the use of overly technical language. In Germany, the contributions of Decker and Jesse (2016) and of Masala (2017) also criticise similar developments and bemoan the lack of academic contributions to important public debates. These critiques led to a slew of responses (e.g. John 2013; Stoker et al. 20I5; Debus et al. 20I7; Zeitschrift für Politikwissenschaft 20I7) that mostly defended the field. Three types of counter-arguments stand out: first, there was never a 'golden age' when political science was highly influential in public debates; second, professionalization is a positive development if it leads to more rigorous research; third, political scientists have recently increased their efforts at reaching out to the public. In this article, we will suggest how the relevance of political science research can be achieved and how these steps can be implemented in the context of a relatively small country such as Austria.

Our general proposition in this article is that political science becomes relevant when its theories and findings are applied to real-world problems outside the academic realm. In developing this argument, we focus on empirical political science, since we believe that the production of knowledge and thus the establishment of relevance follow very different trajectories in (normative) political theory. By empirical political science, we refer to all political science research that collects data (qualitative or quantitative) to answer its research questions. While this may exclude a good part of normative scholarship in practice, it does not do so in principle. Of course, normative aspects may both motivate and arise from empirical work, but in our view the substance of empirical work should strive to be independent of a researcher's preferred conclusions.

We identify four factors that contribute to the relevance of our research: I) the importance of the problem studied, 2 ) the generalizability of the findings, 3) the rigour of the research design, and 4) the accessibility of the research to the non-academic world. In our contribution we aim at highlighting the conditions under which these four criteria are likely to be met.

First, studying important problems ('big questions') is often said to be at odds with conducting rigorous empirical research. Indeed, one of Decker and Jesse's (2016) key criticisms of the field is that political scientists are too timid in tackling big questions. Yet answering such questions does not require us to compromise on methodological rigor, doing so is just more difficult with a high degree of precision. Therefore, researchers need to engage in a division of labour. To begin with, all big questions can be disaggregated into many smaller ones. Next, knowledge from studies on those many smaller questions must be accumulated over time, and finally synthesized to arrive at a big-picture view.

Second, to be relevant our research needs to be applicable to real-world problems. On occasion, research might address a specific, even narrow question that is of immediate societal importance. However, to have a longterm, broader impact, research needs to achieve a minimum degree of generalizability. To do so, empirical work needs to be connected to theoretical explanations and abstract from the cases we observe to draw inferences about other cases.

Third, high-quality research is not achieved by the method chosen, but by the rigor and appropriateness of the research strategy for providing answers to our research question. In choosing research designs, we should be guided by whether we intend to make descriptive or causal inferences from our observations.

Fourth, societal relevance requires that the public, policy-makers, and civil society are (made) aware of our research. This means that researchers need to focus on more than publishing journal articles behind forbidding paywalls. Instead, they need to communicate important findings in various ways in order to reach a broad, generalist audience.

Based on these criteria, we discuss several steps that could be taken to improve the academic and societal relevance of political science in Austria. Those who not only work in Austria but also on Austria need to think carefully about what research on this particular case can contribute to answering big questions. Certainly, developing an international and comparative perspective is all the more important. Also, specialization demands from small scientific communities the courage to leave gaps ("Mut zur Lücke"), in order to strengthen their strengths. Finally, smallness nevertheless also has the advantage of creating relatively short distances between the scientific community, policy-makers, and civil society (although this may vary significantly depending on researchers' local environments).

\section{Importance}

It is almost trivial to state that answers to 'big questions' are more relevant than smaller ones. As researchers, we have to decide how we want to make use of our scarce resources, mostly time and money. Given these resource constraints, it is unsurprising that we would rather devote our energy and 
attention to problems that are of greater importance. The importance of the problem studied is thus a necessary condition for research to be relevant and should therefore constitute a central criterion in the - typically unstructured - process of selecting research questions. To put it bluntly: if the problems we study are not important, then our research is not going to be particularly relevant.

Of course, which questions and problems are important and which are not is in the eyes of the beholder. Certainly, what is important depends on societal context and shifts over time. For instance, Thomas Piketty's book Capital in the Twenty-First Century (2014) successfully placed economic inequality at the centre of both academic research and politi-

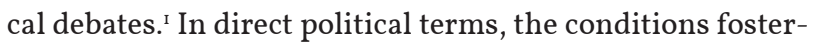
ing elite and voter populism have become a central concern to many, not least since the Brexit referendum and Donald Trump's election. As researchers, we should not chase after fads, but should nevertheless try to answer questions that contribute to understanding how central societal patterns and developments - inequality, discrimination, even wars - come about and, perhaps even more importantly, how problems and conflicts can be addressed and resolved.

Before we attempt to address such "big" questions, it is worth noting that there is a real trade-off between the "size" of a research question and the degree of precision with which it can be answered. Answering big questions especially when trying to generalize across space and time - typically requires researchers to take a bird's eye view and focus on the big picture they find in their data. Such broader contributions are essential and can often move public and academic debates forward; think of Piketty's Capital. But the community of researchers is too large for everyone to focus on composing such a grand oeuvre, and it is important to note that Piketty's work was built on years of painstaking, detailed research initially published in academic peerreviewed journals.

Moreover, a bird's-eye perspective necessarily runs the risk of ignoring some of the idiosyncratic and noisy, yet essential detail that is central to all empirical work. Consider the example of one of the most famous regime classifications in political science - the Three Worlds of Welfare Capitalism. Based on coding social insurance programs in 1980 , Esping-Andersen (1990) found that Western democracies could be neatly grouped into three clusters: the liberal, the conservative-corporatist, and the social democratic regime. Yet years later, a replication effort by Scruggs and Allan (2006) showed that, once Esping-Andersen's coding decisions were scrutinized in greater detail (and errors were corrected), the picture that emerged was much less clear-cut. The results made the authors question "whether it is even meaningful to speak of "welfare regimes"” (2006, 68 ). Of course, by the time Scruggs and Allan had published

I In his book, Piketty argues that, if the return on capital is greater than economic growth in the long term, the concentration of wealth inevitably increases. their replication, the Three Worlds classification had already achieved iconic status in the discipline. Even today, it continues to serve as a first approximation for understanding cross-national variation in welfare regimes.

This example illustrates the fact that, in order to jointly maximize (I) the importance of the questions under study and (2) the empirical precision of our answers to these questions, it is necessary to conceive of social inquiry as a long-term collaborative effort in which hundreds or even thousands of researchers are engaged over longer periods of time. The division of labour between these researchers allows us to tackle the "big question" problem by breaking it into three steps: disaggregation, cumulation, and synthesis.

First, all big questions can be split into smaller ones that are less unwieldy to tackle with the resources that any individual researcher (or small team of researchers) will typically command. Instead of addressing the long and complex causal chains that connect two broad and important phenomena (How do political institutions affect human well-being?), it is possible to focus on smaller sub-questions or individual links in these causal chains (What is the impact of electoral systems on social spending?). Zooming in on narrower questions typically allows for a more precise empirical answer.

Care needs to be taken in choosing these smaller, manageable questions. Often, as political observers we are fascinated by particular phenomena: Why is party membership higher in Austria than elsewhere? Why does Austria impose such high monetary costs on residents trying to obtain citizenship? And why did Peter Pilz leave the Austrian Green party to run as a candidate on his own party list in the 2017 general election? These questions are important and consequential, but they may remain narrow and add little to progress on bigger questions unless they can be linked to broader debates, such as why people join parties, how countries develop citizenship policies and why parliamentarians defect.

Second, to achieve progress on the big questions, it is necessary that studies on smaller sub-questions reference and build upon previous research and thus accumulate knowledge over time. This requires that scholars acknowledge and speak to each other's work and in that process weed out theoretical arguments and empirical approaches with no or little explanatory power. An example is research on coalition formation, where early office-based rational choice models (Riker 1962; Leiserson 1966) were first supplemented with policy-based approaches (Axelrod I970; De Swaan 1973) and later amended by more institutionally informed theories (e.g. Laver/Shepsle 1996). With the arrival of more sophisticated methods of statistical analysis, the predictions derived from these approaches could finally be tested against one another (Martin/Stevenson 200I).

Third, once knowledge has accumulated through many individual studies on smaller questions, the next step is to synthesize the findings in light of the big questions we 
would like to address. A recent example is Achen and Bartels' (2016) Democracy for Realists. In this book the "folk theory" of democracy, by which enlightened citizens carefully weigh their options to arrive at a rational voting decision, is mercilessly shot down using decades worth of research on how cognitive biases, partisanship, and group identities shape - or rather: distort - electoral behaviour. Note that Achen and Bartels' book could not have been written in the same way without this large body of work based on incremental advances on smaller questions. So, tackling the big questions in satisfactory and convincing ways is not an alternative to but rather the culmination of more detailed work.

Also, the "bigger" a research question, the more likely it is to stretch beyond the borders of a single discipline. The division of labour that is necessary to accumulate knowledge from many smaller studies into one big-picture view thus also happens across disciplines (Decker and Jesse 2016). A strong interdisciplinary perspective is thus often necessary to achieve knowledge accumulation across disciplinary boundaries. The more open empirically-minded political scientists are to developments in neighbouring fields such as economics, sociology, communication science, psychology, or anthropology, the easier it will be for them to synthesize research findings into one big picture.

The triple process of disaggregation, cumulation, and synthesis is typically a long-term process that is often chaotic and idiosyncratic. The main reason for this is a lack of coordination by researchers from different countries and disciplines with very different career stages and funding opportunities. A quicker, and perhaps more clever, way to conduct research on "big questions" is foresight and planning; a collaboration of (potentially interdisciplinary) researchers with the ultimate goal of synthesizing their findings at the end of a research project. Vehicles for such collaborative research projects exist (e.g. Special Research Programmes by the Austrian Science Fund FWF), but they are resource-intensive and thus it is notoriously difficult to secure funding for these research endeavours.

\section{Generalizability}

The academic and societal relevance of empirical political science also increases with its scope: knowledge that is applicable to a large population of cases is preferable to that tied to particular contexts or events. There are certainly singular events that need to be studied in isolation. However, to have a long-term, broader impact, research needs to generalize to acquire knowledge on a broader universe of cases.

An answer to a research question may be good if it provides a convincing explanation of what happens, why, and when. In other words, it lays out a coherent theory that identifies the relevant actors and institutions, makes assumptions about their decision-making processes, and entails propositions about outcomes we might observe. So, the contribution our answer can make is by providing new ideas and explanations for events and developments. Ideally, this theory should make clear testable claims that can then be evaluated against the evidence.

Theories should help us to do more than to explain one event: they provide potential answers to a broad universe of cases. Some researchers develop theories inductively and extrapolate from particular events to draw inferences about similar events and developments. Others proceed deductively by stating general propositions that they apply to particular cases. Yet, both induction and deduction increase the level of abstraction so that explanations can be applied to many different contexts. In this process, researchers often face a trade-off between a theory's generalizability and its parsimony (Kellstedt/Whitten 2013, 45): to increase the scope of a theory, it might be necessary to add additional explanatory factors or conditions in the theoretical framework. There is no gold standard for solving this dilemma other than the general advice that we should aim to "explain as much as possible with as little as possible" (King et al. 1994, 29).

The aim of generalization is to go beyond the case(s) we know and to make inferences about the cases we have not yet observed. In this way, we can take knowledge from the cases we have studied to understand cases about which we have less information. These cases may be in the past or in the future, or in other country contexts. The best theories are the ones that (at least most of the time) provide insightful knowledge and accurate predictions about these cases. In contrast, a theory that is not supported by the new empirical evidence may need to be corrected. In that sense, research is usually a "dialogue" between theory and data (Gschwend/ Schimmelfennig 2007).

Some may argue that research on Austria faces limitations due to the country's relatively small size and unique history: can a general approach capture the idiosyncrasies of individual political phenomena in Austria? Shouldn't we study Austrian events or cases as "unique" entities without bothering about generalizability? We think that this approach would throw the baby out with the bath water. All political phenomena are in some sense unique (King et al. 1994, 42-43), but there are also many commonalities that help us to explain other phenomena in different temporal or spatial contexts. Political science research on Austria is no exception to this rule. The Austrian case is a particularly striking one in many research fields, and thus has high potential to add to comparative research on the respective subjects. For example, Austria is an archetypal case for the European model of constitutional review (Stone Sweet 20I4), the electoral fate of Social Democrats (Kitschelt 1994a;1994 b) and the political success of the radical right (McGann/Kitschelt 2005), making it an interesting case for comparison with other European countries. Austria is 
also an outlier in terms of relatively high party membership rates (van Biezen et al. 20I2). We think these are assets, rather than liabilities, that can help make Austria more visible on the international scientific landscape.

\section{Rigour}

How can we answer our research question in a rigorous fashion? Here, we do not want to get into discussions about different theoretical frameworks for explaining phenomena such as political behaviour, institutional change, and international cooperation. Rather our focus is on the empirical part of the answer to a research question: what is the best way to provide empirical evidence for the claims our theory makes?

The first aspect of rigorous research design is that we need to choose designs that are appropriate to answering the questions we ask. There is no single "correct" method that can answer all research questions. Instead, we must choose that approach from our methodological toolbox that is best suited to our task. When it comes to descriptive work, detailed research based on archival sources and interviews is often indispensable. Similarly, large-scale surveys often aim to capture current attitudes, and here high-quality sampling and careful questionnaire design are key.

However, much of the focus of research in the social sciences lies on explaining phenomena rather than describing them. The question of how to explain phenomena has recently been the focus of extensive discussion in the social sciences. The key criticism is that past research was too limited in its ability to fully establish causal linkages. Too often, quantitative researchers employed approaches based on regression models that can only ever imperfectly capture causal connections. Similarly, researchers making use of qualitative approaches frequently claimed causality based on limited, imperfect evidence.

In response to this, the discipline has recently re-oriented itself towards methodological approaches that can do a better job of establishing causality (Angrist/Pischke 2008, Morgan/Winship 2014). One approach has been to rely increasingly on experimental methods (Druckman et al. 20II). These methods are broad and varied. The most labour-intensive are surely field experiments, for example on persuasion and mobilization effects in campaigns or on the impact of development interventions (Banerjee/Duflo 2OII; Gerber/Green 2OI2). Experiments can also take place in laboratory settings or can be embedded within surveys (Mutz 20II). By controlling the size of the treatment and the assignment of participants to the treatment, experiments can do better than other approaches at establishing causality. Of course, this clarity may sometimes come at the cost of external validity: experimental settings may differ in important ways from those in the real world. For instance, studying media effects in experiments may not replicate real-world exposure to news. Experiments can show effects are plausible, but they cannot replace all other methods.

Researchers have also used the experimental method to develop new research designs for observational data. Here, the aim is to find quasi-experimental settings where the real world, generally by accident, creates situations that are similar to those that could have been generated experimentally (Dunning 20I2). For example, Becker et al. (2016) use such a design to study the long-run impact of the Habsburg Empire on public-sector corruption in Central and Eastern Europe. The types of designs that fall under this approach are manifold, but prominent designs include natural experiments, instrumental variables and regression discontinuities.

These methodological debates concerning the assessment of causality have implications for political science research in Austria. In order to participate in developing the state-of-the-art of the discipline, researchers need to focus on their ability to provide high-quality causal claims concerning relationships between variables. To do so, they need to refer to and apply the newly developed tools that allow for causal inference. The training in such methods needs to be maintained and improved in Austria: for example, training in causal inference should be a core element of doctoral training. In working hard to establish causal relationships, researchers can arrive at findings that are relevant for the broader political science community.

Other research questions are even more fundamental and aim to arrive at underlying understandings of conceptions, understandings and processes. Here, quantitative, causal models may not be appropriate, either because there are too few cases, because large-n data is difficult to collect or because the types of attributes and relationships are difficult to quantify. For example, Cramer (2016) and Hochschild (20I6) used ethnographic methods to map popular attitudes that help us understand rural resentment in the United States, while Mudde (2004; 2007) has provided key conceptual clarifications concerning the ideology of radical right parties and the nature of populism. Another example of prominent qualitative research is process-tracing, which aims to study causal mechanisms that link causes to outcomes (Beach and Pedersen 20I3). These research efforts add significantly to our knowledge and understanding of political phenomena, even if their claims regarding the causal relationships are perhaps limited. These examples show how qualitative methods continue to be essential. What is important is that we are aware of what given methods can and cannot do.

Indeed, qualitative research continues to play an underacknowledged role in quantitative research as well. The questions researchers ask and the type of data they collect is often informed by their (qualitative) interpretations of the world around them and the factors that may cause the phenomena they want to analyse. Survey research is a good example of this. The questions included in surveys are partly based on past research and scholarly findings. Often, 
they are also based on intuitions concerning important attitudes and key citizen characteristics. Moreover, surveys themselves need qualitative input, particularly in the form of cognitive interviews, which can be used to grasp how questions are understood and to probe the associations raised by words and phrases (Willis 2004). Similarly, quantitative content analysis relies on qualitative inferences when codebooks are developed. Some of the most advanced quantitative content analysis methods - for instance topic modelling - also require qualitative judgements. Hence, even quantitative work has to be qualitatively informed.

Finally, our aim should be to establish shared standards concerning transparency and replicability in our research. An international effort to establish such standards is the Data Access and Research Transparency (DART) initiative, which aims to make it easier evaluate the empirical foundation of political science research (www.dartstatement.org). To do so, it suggests that the data researchers use should be made openly accessible. In addition, the steps the researchers took to analyse their data should be transparent. The aims of this initiative are threefold: to ensure scholarly integrity, to allow for re-analysis of existing data, and to make findings publicly available.

At first glance, these aims might appear to relate mostly to quantitative data: the datasets used should be made available in open depositories, and the steps used to carry out the analysis should be included there as well. However, the DART initiative is also aimed at qualitative researchers, who also make empirical claims based on data they have collected. Hence, qualitative researchers should deposit the text of interviews they have conducted, the field notes they kept during their research or the full references to archival sources. This can guard against accusations of cherry-picking or fabrication. There was some debate about how these guidelines should be interpreted and implemented for qualitative data (see www.qualtd.net). In particular, it was debated in what form qualitative data should be deposited and when confidential data should be made accessible.

Despite these remaining issues, the fundamental aims of the DART initiative are a step forward for the discipline. In order to meet criticism from academic and non-academic audiences, we have to ensure that we maintain high standards of data access and transparency. This may often be burdensome to researchers, so support for these activities must be strengthened. Focusing on Austria, researchers should be encouraged to make use of the new Austrian Social Science Data Archive (AUSSDA), while journals such as the Austrian Journal of Political Science should develop data transparency policies.

\section{Communication}

The last step in the research process is to make our findings available to the public. Dissemination is necessary to make our findings relevant for society: a result hidden away in a locked and sealed library does little to add to our knowledge. The more widely results are communicated, the higher their potential impact.

As researchers, we have three potential target audiences: the scientific community (including students), relevant practitioners and the broader public. These groups naturally differ in the types of information and knowledge they already have, but they also differ in the kinds of findings they will be interested in. When we communicate our findings, we therefore have to tailor our dissemination to the respective target group.

For the scientific community, researchers need to do least to adapt traditional forms of dissemination, as this is the most established kind of knowledge transfer. Our aim should be to help build a body of knowledge that other scholars can use to construct and develop their own theories, as we ourselves did in basing our research on previous findings and other cases. Otherwise, scientists cannot "stand on the shoulders of giants" and remain dwarves instead. Contributing to the international research community is especially important for a rather small country such as Austria. Its national scholarship, valuable as it might be, is simply not big enough to reach a critical mass on its own.

To enable the communication between scientists, three important conditions have to be met. First, we must literally speak the same language. In the past, Latin and French have been prominent; nowadays, English is the lingua franca of scholarly communication. For Austrian researchers, this means that writing in German is not necessarily the best way of maximizing readership inside the scientific community - yet it is often the best approach when trying to reach other audiences.

Second, research must be available to peers. Today, research is often found via online search engines, so it is important to make our research available on as many platforms as possible, be they personal webpages, institutional repositories or networks such as the Social Science Research Network (SSRN), ResearchGate, or Academia.edu. ${ }^{2}$

Third, we have to ensure that our research is eventually published in high-quality outlets, be they journals or university presses. Despite their often antiquated processes and inaccessible paywalls, peer-reviewed journals remain the key way to publish research findings if the aim is to reach broad audiences within the discipline. Publishing in respected journals has two benefits for authors and readers. First, even if imperfect, peer review still helps to ensure quality and rigour in scientific research, so we can expect research published in good journals to meet a certain standard. This also means that we as authors have to try to match those standards (Debus et al. 20I7). Second, journals differ in their topical focus and methodological outlook, so they

2 As of 20I6, all three of those networks are commercially owned, which poses an entirely different set of problems. 
serve as useful heuristic in sifting through the large amount of past work. This is especially important in the internet era where scholars need to distinguish solid scientific research from the flood of poorly conducted pseudo-studies. Hopefully, open access will become more available and affordable over time, ensuring the role of journals in the twenty-first century. Nevertheless, we agree with Nielsen (2018: I46) that 'the combination of open-ended empirical inquiry, the sharing and accumulation of insights across a community, and the evolution and enforcement of shared standards that enable scientific knowledge production requires something like the imperfect institution of peer review.'

However, researchers need to do more than just to communicate to their peers. Most of the research in Austrian universities is paid for by public resources, and researchers in turn have an obligation to share their data and findings. This "third mission" (next to teaching and research) can happen in various forms such as giving advice to policymakers, data sharing, blogs, public lectures or interviews. ${ }^{3}$

For one, we need to talk to practitioners: those people in ministries, parliaments, interest groups and nongovernmental organizations who make policy, as well as the journalists who cover them. For these audiences, we need to communicate our findings in ways that highlight specific problems and answers. A party politician will not care about general theories of human behaviour, but may pay attention to the consequences of potential reforms. One example for such an interaction is the research project "Voting at 16 at the 2013 Austrian general election" (Kritzinger et al. 2013). In their project, Kritzinger et al. studied the engagement and knowledge of young voters after the voting age had been lowered from 18 to 16 in the 2007 electoral reform: does lowering the voting age lead to more or less political interest, knowledge, and political participation among younger voters? Analysing these questions provides valuable feedback to policy-makers which is crucial to understand and to evaluate the effect of their reforms.

We also need to engage with society at large. Of course, this is a diverse group that is very heterogeneous in its interests and prior knowledge. However, society benefits if important debates are informed by scholarly research, hence by facts and evidence. The most crucial thing to keep in mind in all these activities is that knowledge transfer should always be based on actual research output. Perhaps the most straightforward way to engage with the broader society is to feed research results into newspaper articles or other mass media formats. For example, the science-related article with the largest number of user comments in the Austrian newspaper website "Der Standard" in 2017, was an article dealing with findings from political science rather

3 These forms of research output are very diverse and notoriously difficult to measure. Despite recent attempts to quantify such forms of societal impact, there is yet no "gold standard" for classifying and evaluating such research outputs. Most university rankings ignore the societal impact factor altogether. than one about history, biology or physics (Der Standard, 4 January 20I8). ${ }^{4}$

Engagement with the broader public is, of course, a reciprocal process and in itself not without problems. It entails not only communication with journalists, but also responsiveness to topics and interests we (as scientists) are confronted with. That is, not only should we communicate our own ideas and findings, but we should also listen to the issues and concerns of other actors in the society at large. This is not an easy process as all actors have their own interests and constraints. For example, policy-makers might be more interested in practical solutions rather than sound theories, while journalists and editors have their own 'media logic' when covering news stories. Despite these difficulties, we believe it is crucial for political scientists to engage in this dialogue.

\section{Summary and implications}

One of the most challenging tasks for empirical researchers can be to understand and explain how exactly our research is relevant and consequential for the discipline and for society in general. We have tried to provide some guidelines that we believe researchers should keep in mind when conducting their studies. The questions we need to ask ourselves when conducting and writing up our research are:

- How do the questions we study relate to broader questions relevant to the discipline and society?

- How does the theory we develop build on and extend existing approaches?

- How do our findings complement or contradict existing work, and to what extent can they be applied to different contexts?

- How do our findings change our thinking about key societal problems and challenges?

- How can policy-makers, practitioners and the general public benefit from the results of our research?

We suggest that, by answering these questions, the research we design and conduct will be more academically and societally relevant, both inside and outside of Austria.

Finally, young researchers face particular challenges. They are beginning their careers in a rather competitive professional context. Young scholars in particular may find that they have greater incentives to engage in research that is valued in their discipline rather than doing work that has high societal relevance (Savage 2013). Some employers in universities and research institutions certainly pay too much attention to the ranks of journals and the number of publications and neglect the quality and potential impact of young researchers' work. We cannot, at this point, offer

4 In this article, Tanja Draxler (2017) reports about findings by Sylvia Kritzinger and Julian Aichholzer about the policy preferences of FPÖ voters. 
a remedy for this problem, yet any attempt at addressing it will include moving broader relevance up the list of criteria by which we evaluate each other's work. We see it as encouraging that journal editors and reviewers place increasing emphasis on the need for research to spell out clearly and effectively how it adds to our knowledge and contributes to our understanding of the world.

\section{References}

Achen, Christopher H./Larry M. Bartels (2016), Democracy for realists: Why elections do not produce responsive government, Princeton, NJ: Princeton University Press.

Angrist, Joshua D./Jörn-Steffen Pischke (2008), Mostly harmless econometrics: An empiricist's companion, Princeton, NJ: Princeton University Press.

Axelrod, Robert (1970), Conflict of Interest, Chicago: Markham.

Banerjee, Abhijit V./Esther Duflo (20II), Poor economics: A radical rethinking of the way to fight global poverty, New York: Public Affairs.

Beach, Derek/Rasmus B. Pedersen (2013), Process-tracing methods: Foundations and guidelines, Ann Arbor: University of Michigan Press.

Becker, Sascha O./Katrin Boeckh/Christa Hainz/Ludger Woessmann (2016), The empire is dead, long live the empire! Long-run persistence of trust and corruption in the bureaucracy, in: The Economic Journal, I26(590), 40-74.

Biezen, Ingrid van/Peter Mair/Thomas Poguntke (2012), Going, going, ... gone? The decline of party membership in contemporary Europe, in: European Journal of Political Research 5I(I),24-56.

Cramer, Katherine J. (20I6), The politics of resentment: Rural consciousness in Wisconsin and the rise of Scott Walker, Chicago and London: University of Chicago Press.

Debus, Marc/Thorsten Faas/Armin Schäfer (20I7), Ist die Politikwissenschaft irrelevant? in: Frankfurter Allgemeine Zeitung, 17.05.2017, Internet: http://www.faz.net/aktuell/politik/inland/einfluss-auf-debatten-ist-die-politikwissenschaft-irrelevant-I5OI9746.html (accessed: 09.0I.2018).

Decker, Frank/Eckhard Jesse (2016), Fach ohne Ausstrahlung, in: Frankfurter Allgemeine Zeitung, 20.04.2016, Internet: http://www.faz.net/aktuell/feuilleton/forschung-undlehre/politikwissenschaft-und-ihre-lage-der-in-deroeffentlichkeit-I4I86054.html (accessed: 09.0I.20I8)

Der Standard (2018), Zehn Zankäpfel: Die meistdiskutierten Wissenschaftsartikeldes Jahres, 04.OI.2018, Internet:https://derstandard.at/2000071133327/Zehn-ZankaepfelDie-meistdiskutierten-Wissenschaftsartikel-des-Jahres?_slide=IO (accessed: O9.OI.20I8)

Druckman, James N./Donald P. Green,/James H. Kuklinski/ Arthur Lupia (Eds.) (2OII), Cambridge handbook of ex- perimental political science, Cambridge: Cambridge University Press.

Dunning, Thad (2012), Natural experiments in the social sciences: a design-based approach, Cambridge: Cambridge University Press.

Esping-Andersen, Gøsta (1990), The Three Worlds of Welfare Capitalism, Cambridge: Polity Press.

Flinders, Matthew (2013), The tyranny of relevance and the art of translation, in: Political Studies Review, II(2), I49I67.

Gerber, Alan S./Donald P. Green (2012), Field experiments: Design, analysis, and interpretation, New York: WW Norton.

Gschwend, Thomas/Frank Schimmelfennig (Eds.) (2007), Research Design in Political Science: How to Practice What They Preach, Houndmills, Basingstoke: Palgrave/Macmillan.

Hochschild, Arlie R. (20I6), Strangers in their own land: Anger and mourning on the American right, New York: The New Press.

John, Peter (2012), How relevant is UK political science? A riposte to Matthew Flinders and Peter Riddell, I7 April 20I2, Internet: http://blogs.lse.ac.uk/politicsandpolicy/ how-relevant-is-political-science-john/ (accessed: IO.OI.20I8).

John, Peter (20I3), Political science, impact and evidence, in: Political Studies Review, II(2), I68-I73.

Kellstedt, Paul M./Guy D. Whitten (2013), The Fundamentals of Political Science Research, Cambridge: Cambridge Unversity Press.

King, Gary/Robert Owen Keohane/Sidney Verba (1994), Designing Social Inquiry: Scientific Inference in Qualitative Research, Princeton: Princeton University Press.

Kitschelt, Herbert (1994a), Austrian and Swedish SocialDemocrats in Crisis: Party Strategy and Organization in Corporatist Regimes, in: Comparative Political Studies 27(I), 3-39.

Kitschelt, Herbert (1994b), The transformation of European social democracy, Cambridge: Cambridge University Press.

Kritzinger, Sylvia/Eva Zeglovits/Patricia Oberluggauer (2013), Wählen mit I6 bei der Nationalratswahl 20I3, Internet: https://www.parlament.gv.at/ZUSD/PDF/Wahlstudie Waehlen_mit_I6.pdf (accessed: 09.0I.2018).

Laver, Michael/Kenneth A. Shepsle (1996), Making and Breaking Governments: Cabinets and Legislatures in Parliamentary Democracies, New York: Cambridge University Press.

Leiserson, Michael (1968), Factions and Coalitions in OneParty Japan - Interpretation Based on Theory of Games, in: American Political Science Review 62 (3), 770-787.

Martin, Lanny W./Randolph T. Stevenson (200I), Government formation in parliamentary democracies, in: American Journal of Political Science 45(I), 33-50. 
Masala, Carlo (20I7), Auf dem Rückzug, in: Zeit Campus, 23.02.2017, Internet: http://www.zeit.de/2017/o7/politikwissenschaft-wissenschaftler-forschung-gesellschaftliche-relevanz (accessed: 09.0I.20I8).

McGann, Anthony J./Herbert Kitschelt (2005), The radical right in the Alps: Evolution of support for the Swiss SVP and Austrian FPO, in: Party Politics II(2), I47-7I.

Morgan, Stephen L./Christopher Winship (2014), Counterfactuals and causal inference, Cambridge: Cambridge University Press.

Mudde, Cas (2004), The populist zeitgeist, in: Government and opposition, 39(4), 54I-563.

Mudde, Cas (2007), Populist radical right parties in Europe, Cambridge: Cambridge University Press.

Mutz, Diana C. (201I), Population-Based Survey Experiments, Princeton: Princeton University Press.

Nielsen, Rasmus K. (2018), No One Cares What We Know: Three Responses to the Irrelevance of Political Communication Research, in: Political Communication, 35 (I),I45I49.

Piketty, Thomas (2014), Capital in the Twenty-First Century, Cambridge und London: Harvard University Press.

Riker, William H. (1962), The Theory of Political Coalitions, New Haven: Yale University Press.

Savage, Lee (20I3), A View from the Foothills: Public Engagement among Early Career Researchers, in: Political Studies Review, II(2), 190-199.

Scruggs, Lyle/James Allan (2006), Welfare-state decommodification in 18 OECD countries: a replication and revision, in: Journal of European Social Policy, I6(I), 55-72.

Senn, Martin/Franz Eder (2018), The Relevance of (Austrian) Political Science: A Conceptual Framework, in: ÖZPAustrian Journal of Political Science, Vol. 47(3), I-I7.

Stoker, Garry/B. Guy Peters/Jon Pierre (Eds.) (2015), The Relevance of Political Science, London, Palgrave.

Stone Sweet, Alec (2014), Constitutions and judicial power, in: Caramani, Daniele (Ed.), Comparative Politics, Oxford: Oxford University Press, I50-I65.

Swaan, Abram de (1973), Coalition Theories and Government Formation, Amsterdam: Elsevier.

Traxler, Tanja (20I7), FPÖ-Wähler stehen ökonomisch weiter links als die Partei, in: Der Standard, 21.12.2017, Internet: https://derstandard.at/2000070788364/FPOe-Waehler-stehen-oekonomisch-weiter-links-als-die-Partei (accessed: 09.0I.2018).

Willis, Gordon B. (2004), Cognitive interviewing: A tool for improving questionnaire design, London: Sage Publications.

Zeitschrift für Politikwissenschaft (20I7), Schwerpunkt: Quovadis, deutsche Politikwissenschaft?, 27 (I).

\section{Authors}

Laurenz Ennser-Jedenastik is a post-doctoral researcher at the University of Vienna's Department of Government. His work focuses on parties, elections, political elites, bureaucracy, and social policy. He has published in numerous international journals and also runs a weekly blog on Austrian politics at derstandard.at/abweichung.

Thomas M. Meyer is an Associate Professor for Government at the University of Vienna. His research focuses on elections, political competition, voting behaviour, and coalition governance.

Markus Wagner is a Professor in the Department of Government at the University of Vienna. His research focuses on the role of issues and ideologies in vote choice and party competition. 